\title{
Kajian Eksperimental Permodelan Numerik Resistivitas-Korosivitas
}

\author{
Hamzah Abdullah Mubarak, Anik Hilyah, dan Widya Utama \\ Departemen Teknik Geofisika, Fakultas Teknik Sipil dan Perencanaan, Institut Teknologi Sepuluh Nopember (ITS) \\ e-mail: anik.hilyah@gmail.com
}

\begin{abstract}
Abstrak-Metode Resistivitas merupakan metode yang dapat memberikan informasi mengenai tahanan jenis sebuah media, salah satunya media seperti tanah. Tahanan jenis yang rendah pada tanah tersaturasi fluida dapat mengindikasikan kondisi lingkungan yang konduktif. Lingkungan yang konduktif berpotensi menciptakan korosi pada logam umumnya dan khususnya besi. Permodelan numerik resistivitas-korosivitas digunakan untuk mengkorelasikan parameter resistivitas dengan parameter korosivitas seperti laju korosi. Sehingga dari permodelan numerik tersebut dihasilkan persamaan numerik yang dapat mencitrakan laju korosi yang berpotensi terjadi dari hasil penampang resistivitas. Permodelan numerik resistivitas untuk menganalisis laju korosi ini dapat digunakan untuk melakukan kontroling pipa yang ditanam di bawah tanah. Pada Studi ini dilakukan permodelan resistivitas terhadap laju korosi dari data uji labolatorium terhadap sampel besi AISI 1045 dengan memberikan variasi konsentrasi larutan $\mathrm{NaCl}$ terhadap media, dan variasi waktu pengukuran laju korosi. Hasil akhir dari penelitian ini berupa persamaan numerik yang merepresentasikan hubungan antara resistivitas terhadap laju korosi. Persamaan numerik tersebut adalah $C R=0,1844 \rho^{-0,187}$.
\end{abstract}

Kata Kunci-Korosi, Korosivitas, Resistivitas.

\section{PENDAHULUAN}

$\mathrm{K}$ OROSI kini merupakan suatu kendala yang merugikan dunia industri, khususnya pada perusahaan yang memanfaatkan pipa berbahan logam. Setidaknya korosi logam di seluruh dunia telah menimbulkan kerugian sebesar 2.2 triliun USD [1]. Penanganan korosi sejak dini terhadap logam dinilai mampu mengurangi kerugian tersebut sebesar 25-30\%. Korosi merupakan proses degradasi logam yang diakibatkan oleh senyawa kimia atau reaksi elektrokimia logam dengan lingkungan.

Pada implementasinya, biasanya logam dimanfaatkan untuk dijadikan pipa karena kekuatannya. Ketika pipa dikubur di dalam tanah, pipa berbahan logam biasanya lebih kuat dibandingkan dengan pipa PVC. Namun ada konsekuensi yang perlu diperhatikan, hal tersebut yaitu pipa akan terisolasi di bawah tanah. Pipa logam yang terisolasi di bawah tanah tentunya akan berinteraksi dengan lingkungan sekitar yang dapat menyebabkan terjadinya korosi, sehingga jika dibiarkan dalam jangka waktu yang lama akan merusak logam itu sendiri (Romanoff). Korosivitas tanah dapat didefinisikan sebagai kemampuan tanah untuk merusak logam terhadap permukaan logam yang diukur melalui laju korosi [2]. Laju korosi pada permukaan pipa logam yang berada di dalam tanah tentunya tidak seragam. Untuk memantau lingkungan pipa di bawah tanah tersebut guna menganalisis korosi yang terjadi, perlu dilakukan pemantauan terhadap lingkungan pipa di bawah tanah. Salah satu parameter lingkungan bawah tanah adalah resistivitas tanah. Dengan mengetahui hubungan resistivitas tanah dengan laju korosi, tentunya bisa dilakukan pemantauan lingkungan tanpa harus menggali tanah terlebih dahulu.

Karena itu perlu diketahui hubungan antara resistivitas tanah dengan laju korosi yang menyebabkan terjadinya korosi pada logam. Pada kegiatan Studi yang penulis laksanakan ini, dapat diketahui hubungan antara parameter resistivitas tanah dengan korosivitas logam melalui persamaan numerik. Persamaan numerik hasil penelitian ini dapat digunakan untuk mengkonversi nilai resistivitas menjadi nilai korosivitas dan mampu memberikan interpretasi kuantitatif penampang lingkungan korosif.

\section{TINJAUAN PUSTAKA}

\section{A. Metode Geolistrik}

Geolistrik merupakan salah satu metoda geofisika untuk mengetahui perubahan tahanan jenis lapisan batuan di bawah permukaan tanah dengan cara mengalirkan arus listrik DC ('Direct Current') yang mempunyai tegangan tinggi ke dalam tanah. Injeksi arus listrik ini menggunakan 'Elektroda Arus' yang ditancapkan ke dalam tanah pada jarak tertentu. Semakin panjang jarak elektroda arus, akan menyebabkan aliran arus listrik bisa menembus lapisan batuan lebih dalam. Dengan adanya aliran arus listrik tersebut maka akan menimbulkan tegangan listrik di dalam tanah. Tegangan listrik yang terjadi di permukaan tanah diukur dengan penggunakan multimeter yang terhubung melalui “Elektroda Tegangan' yang jaraknya lebih pendek dari pada jarak elektroda arus. Bila posisi jarak elektroda arus diubah menjadi lebih besar maka tegangan listrik yang terjadi pada elektroda potensial ikut berubah sesuai dengan informasi jenis batuan yang ikut terinjeksi arus listrik pada kedalaman yang lebih besar [3].

\section{B. Metode Resistivitas}

Salah satu metode geolistrik adalah metode tahanan jenis Gambar 1. (A) Definisi dasar dari arus I yang melalui suatu blok resistivitas dengan panjang $\mathrm{L}$ dan beda potensial $\mathrm{V}$ di antara dua luas permukaan $\mathrm{A}$. (B) 


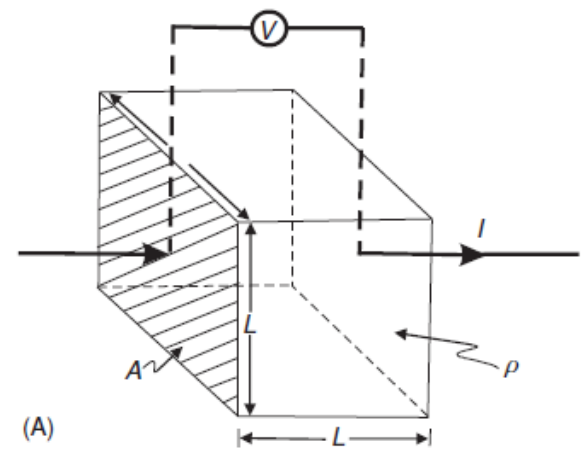

rangkaian listrik yang sebanding, di mana R bertindak sebagai resistor.

(resistivitas). Dengan mengetahui nilai tahanan jenis di bawah permukaan bumi, maka dapat ditentukan banyaknya lapisan penyusun dan jenis material penyusun. Metode resistivitas atau resistivitas merupakan salah satu metode Geofisika yang digunakan untuk penyelidikan bahwa permukaan, dengan mengukur sifat kelistrikan batuan. Batuan merupakan medium yang dapat menghantarkan arus listrik, karena di dalam batuan terdapat elektron dan ion-ion yang menjalar di dalam struktur batuan dan air tanah jika dalam batuan diberikan suatu beda potensial. Dasar yang dipakai dalam metode geolistrik adalah adanya beda resistivitas antar batuan atau medium. Dalam hal ini meliputi pengukuran potensial, arus dan medan elekttromagnetik yang terjadi, baik secara alamiah maupun akibat injeksi arus ke dalam bumi [4].

Diilustrasikan seperti gambar 1, di mana pada balok dengan panjang (L) dialiri arus (I). Material yang terdapat pada balok kemudian akan menahan aliran konduksi listrik yang melaluinya, hingga akan dihasilkan potensial (V) di antara dua luasan permukaan [5].

$\rho=\frac{V A}{I L}$

$$
\begin{aligned}
& \text { Di mana } \\
& \rho=\text { hambatan jenis atau resistivitas }(\Omega \mathrm{m}) \\
& \mathrm{V}=\text { beda potensial }(\mathrm{V} \text { atau } \mathrm{mV}) \\
& \mathrm{A}=\text { luas permukaan plat }\left(\mathrm{m}^{2}\right) \\
& \mathrm{I}=\text { arus listik }(\mathrm{A} \text { atau } \mathrm{mA}) \\
& \mathrm{L}=\text { jarak antar plat }(\mathrm{m})
\end{aligned}
$$

\section{Laju Korosi}

Laju korosi pada umumnya dapat diukur dengan menggunakan dua metode yaitu: metode kehilangan (weight loss) berat dan metode elektrokimia. Metode weight loss menghitung kehilangan berat yang terjadi setelah beberapa waktu manipulasi kondisi pada logam. Pada penelitian ini, dilakukan perhitungan selisih antara berat awal dan berat akhir logam [6].

Satuan laju korosi yang biasa digunakan dalam pengukuran laju korosi metode weight loss yaitu mils per tahun (mpy) dan milimeter per tahun (mmy), persamaan yang digunakan untuk menghitung laju korosi weight loss adalah:
Tabel 1.

Variasi nilai konstanta laju korosi

\begin{tabular}{ccc}
\hline \hline Satuan CR & $\mathrm{A}$ & Faktor K \\
\hline Mils/tahun & $\mathrm{In}^{2}$ & $5,34.10^{5}$ \\
Mils/tahun & $\mathrm{Cm}^{2}$ & $3,54.10^{6}$ \\
Milimeter/tahun & $\mathrm{Cm}^{2}$ & $8,75.10^{4}$ \\
\hline \hline
\end{tabular}

CR - Corrosion Rate

A - Satuan luas

$C R=\frac{\Delta W K}{\rho A T}$

Di mana:

$\mathrm{CR}=$ laju korosi (mmy atau mpy)

$\mathrm{ML}=$ metal loss (mils atau milimeter)

$\Delta \mathrm{W}=$ berat yang hilang $(\mathrm{g})$

$\rho=$ density benda uji korosi $\left(\mathrm{g} / \mathrm{cm}^{3}\right)$

$\mathrm{A}=$ luas permukaan $\left(\mathrm{cm}^{2}\right)$

$\mathrm{T}=$ waktu (jam)

\section{Desain Alat Pengukuran}

Desain alat pengukuran resistivitas yaitu seperti gambar 2, menggunakan dua lempeng tembaga pada kedua ujung pipa PVC. Hal ini dilakukan agar arus yang mengalir melalui seluruh bagian media rekondisi sehingga resistivitas media rekondisi dapat terukur secara keseluruhan.

Setelah dirangkai alat, kemudian dilakukan pengukuran terhadap media rekondisi. Setelah diperoleh nilai potensial dan arus yang konstan, daat diperoleh nilai resistivitas dari perbandingan potensial dalam suatu luasan terhadap arus yang mengalir sepanjang media rekondisi dalam pipa. Perhitungan nilai resistivitas dilakukan dengan menggunakan persamaan 1 dan perhitungan nilai induced polarization dengan menggunakan persamaan 2 .

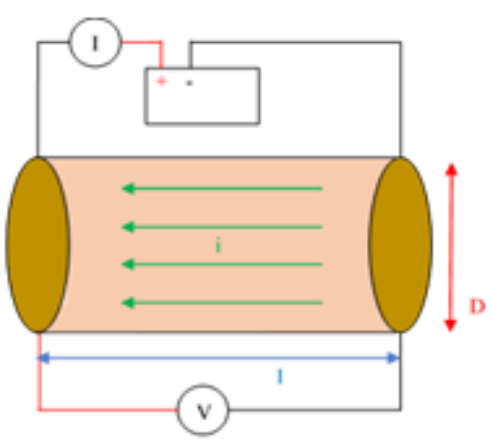

Gambar 2. (Proses pengukuran resistivitas, ketika pengukuran dilakukan, lempeng tembaga diletakkan pada kedua ujung pipa, kemudian kedua tembaga dihubungkan ke voltmeter dan dihubungkan ke aki (sumber potensial) yang telah dirangkai seri dengan amperemeter. 


\section{PEMBAHASAN}

Setelah dilakukan perhitungan dan analisis data, kemudian nilai resistivitas yang telah diperoleh dibandingkan dengan nilai laju korosi. Perbandingan dilakukan dengan cara membuat grafik hubungan kedua parameter, kemudian dibuat garis yang merepresentasikan hubungan kedua parameter.

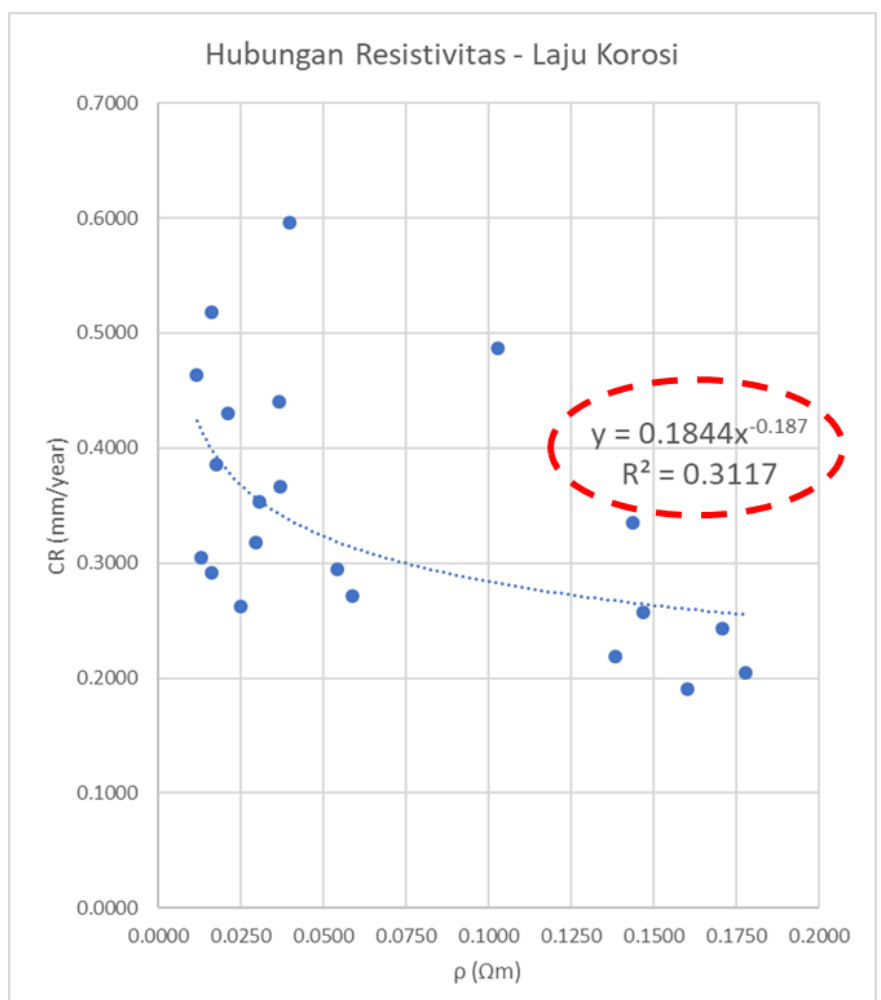

Gambar 3. Hubungan resistivitas dengan laju korosi. Garis arah persebaran data nilai laju korosi terlihat menurun terhadap nilai resistivitas.

Persamaan garis yang diperoleh adalah seperti pada gambar 3. Garis persamaan menunjukkan semakin tinggi nilai resistivitas maka semakin rendah nilai laju korosi yang terjadi. Persamaan garis yang merepresentasikan hubungan antara resistivitas dengan laju korosi adalah.

$C R=0,1844 \rho^{-0,187}$

Konstanta 0,1844 dipengaruhi oleh laju perubahan massa dalam sebuah luas penampang logam terhadap aliran arus listrik (kg.meter ${ }^{2}$.ampere ${ }^{-2}$.detik ${ }^{-2}$ ). Persamaan dapat digunakan untuk mengkonversi nilai resistivitas menjadi nilai laju korosi. Setelah nilai resistivitas dikonversi menjadi nilai laju korosi, selanjutnya saat diperoleh penampang korosivitas tanah, informasi korosivitas tanah dapat diperoleh terlebih dahulu sebelum proses penanaman logam ke dalam tanah. Sehingga anstisipasi korosi terhadap logam dapat ditentukan lebih awal.

\section{KESIMPULAN/RINGKASAN}

Hasil penelitian yang telah dilakukan menunjukkan bahwa hubungan parameter resistivitas terhadap parameter laju korosi dapat dirumuskan dalam $C R=0,1844 \rho^{-0,187}$, di mana CR adalah corrosion rate dalam satuan $\mathrm{mm} /$ tahun, $\rho$ adalah resistivitas dalam satuan $\Omega \mathrm{m}$, dan 0,1844 adalah konstanta yang menunjukkan laju perubahan massa dalam sebuah luas penampang logam terhadap aliran arus listrik (kg.meter2.ampere-2.detik-2).

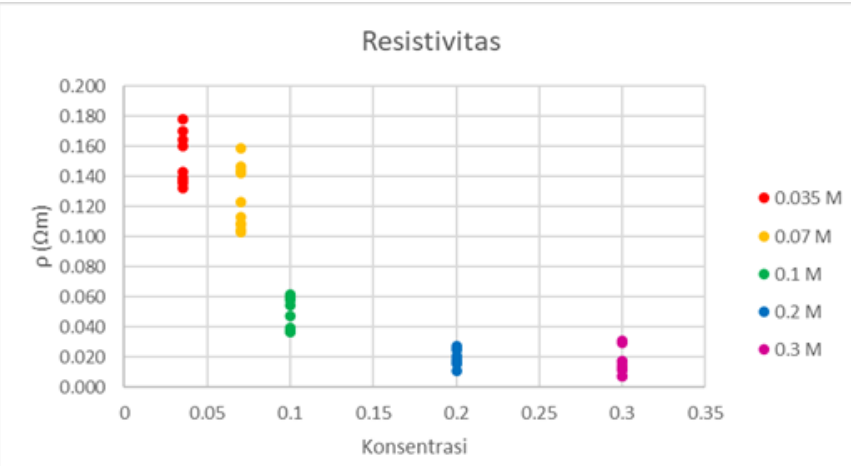

Gambar 4. Kompilasi data resistivitas hasil pengukuran. Sumbu y merupakan laju korosi dan sumbu x merupakan konsentrasi.

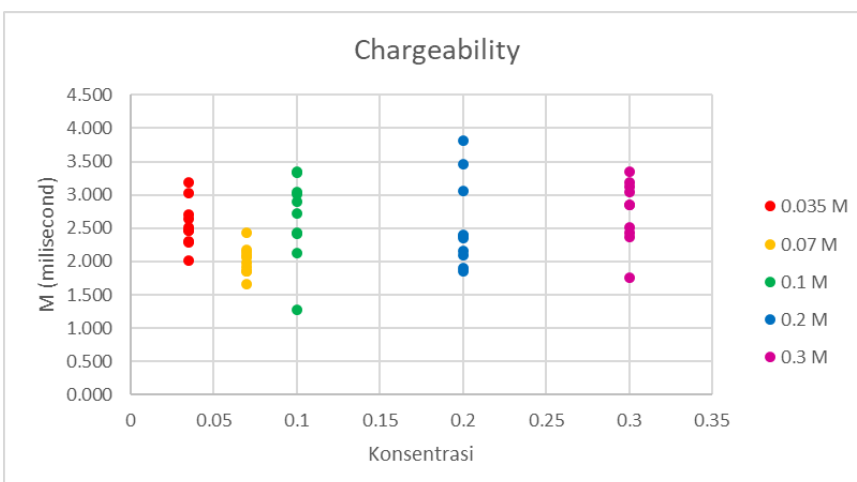

Gambar. 5. Kompilasi data chargeability. Sumbu y merupakan nilai chargeability dalam milisekon dan sumbu $\mathrm{x}$ merupakan konsentrasi dalam molaritas.

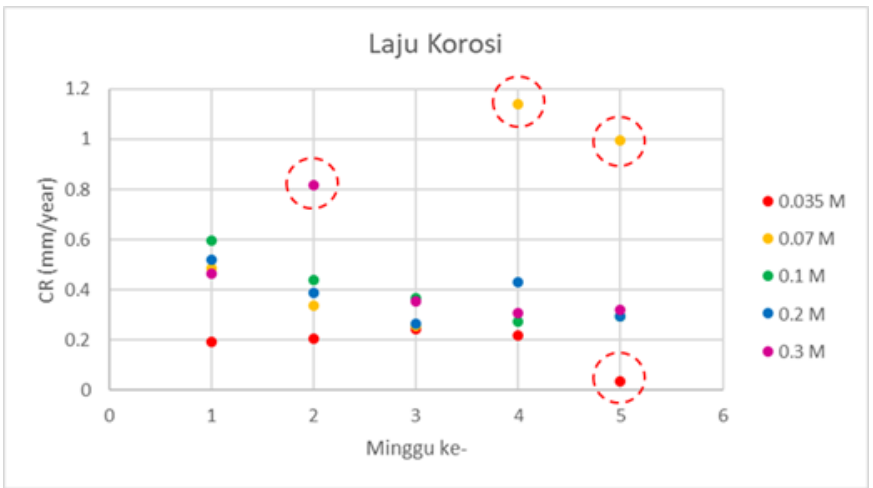

Gambar 6. Kompilasi data laju korosi. Sumbu x merupakan waktu pengukuran weight loss dan sumbu y merupakan laju korosi yang terjadi. Data yang diberikan tanda lingkaran merupakan data yang eror.

\section{UCAPAN TERIMA KASIH}

Penulis mengucapkan terima kasih kepada Direktorat Pendidikan Tinggi, Departemen Pendidikan dan Kebudayaan Republik Indonesia yang telah memberikan dukungan finansial melalui Beasiswa Bidik Misi tahun 2013-2017. Penulis juga 
mengucapkan terima kasih kepada pak. Widya Utama, bu Anik Hilyah, dan pak Andie Soegiarto atas bimbingannya. Temanteman Corrosion Team Rizal, Yuri, Kiki, Amel, dan Lila atas kerja samanya saya ucapkan terima kasih.

\section{DAFTAR PUSTAKA}

$$
\text { G. Association, }
$$

"<URL: https://www.galvanizeit.org/corrosion/effects-of-corrosion>," 2017.
Corrossion and Cathodic Protection," J. Res. Natl. Beureau os Stand. - C. Eng. Instrum., vol. 69C, no. 1, 1965.

[3] dan R. E. S. W. M. Telford, L. P. Geldart, Applied Geophysics. New York: Press New York, 1990.

[4] M. H. Loke, "Electrical Imaging Survey for Environmental and Engineering Studies," 1999.

[5] K. Hooper, Standard Test Method for Measurement of Soil Resistivity Using the Two-Electrode Soil Box Method1. West Conshohocken: ASTM International, 2005.

[6] D. Jones, Principles and Prevention of Corrosion. New York: Macmillan Publishing Company, 1992. 